\title{
Can a Country be Exempted from Impossible Trinity: Evidence from Malaysia
}

\author{
Soo Khoon Goh
}

\begin{abstract}
This paper examines monetary independence during the period when Malaysia had a fixed exchange rate and an open capital account regime. The objective is to assess the relevance of the Impossible Trinity for policy. The evidence of cointegration between the Malaysian and US interest rates during this period, suggests that there is no monetary independence in the long run. However, our results show there is: Malaysia retains some monetary autonomy in the short run. The loss of long-run monetary autonomy under peg/open capital was in line with the trinity, and may be one reason the peg was eventually abandoned for managed floating in July 2005.
\end{abstract}

Index Terms - Impossible trinity, Malaysia.

\section{INTRODUCTION}

The impossible trinity postulates that it is impossible to have a fixed exchange rate regime, an open capital account and an independent monetary policy simultaneously. A country can choose only two of these goals, but not all of them simultaneously. If a country chooses a fixed exchange rate and an open capital account, it means it has to forgo an independent monetary policy. In other words, the cost of maintaining a fixed exchange rate and an open capital account is a loss of control over the domestic monetary policy, as domestic interest rates will be correlated with the pegged country rates. This hypothesis has been widely taught and recognized since it is quite intuitive and helpful to understand the constraints policy makers must face in an open economy setting.

Empirical examination of the nature of these tradeoffs is not abundant. Ohanian and Stockman [1] showed that there can be in fact some room for an independent monetary policy in the short run under a fixed exchange rate regime. Svensson [2] found similar evidence of short-term monetary independence within the EMS. Lim and Goh [3] tested for monetary independence in Malaysia by estimating the capital account offset and sterilization coefficients. Their results are consistent with [1] in that the Malaysian central bank possesses some short-run control over monetary policy even during the fixed exchange rate regime. This is in sharp contrast to the impossible trinity's argument, which states that a country will lose all its monetary independence under fixed exchange rates and free capital mobility.

The objective of this paper is to test the trilemma predictions using a small, emerging market, that is, Malaysia

Manuscript received December 18, 2013; revised February 20, 2014 This work was supported by the Short Term Research Grant, 304/CDASAR/6311107, Universiti Sains Malaysia.

Soo Khoon Goh is with the Universiti Sains Malaysia (e-mail: skgoh@usm.my). in the 2000s. During the Asian Currency Crisis, Malaysia pegged its ringgit to the US dollar and imposed capital controls in Sept, 1998. By May, 2001, Malaysia lifted its capital controls but kept the peg before it removed the peg in July 2005. During this period, the trilemma would predict that Malaysia would have no choice but to give up its monetary autonomy, i.e. allow its interest rates to move closely with the US rates. We aim to examine the correlation between the Malaysian and US interest rates during this period, by using cointegration techniques. The hypothesis is that if the trinity holds, there should be no monetary policy autonomy in Malaysia, when Malaysia has a fixed exchange rate and an open capital account. Interest rates in Malaysia should move closely with the interest rates in US, in order to maintain the pegged exchange rate. Hence, we should find evidence of cointegration between Malaysian and US interest rates from May 2001 till June 2005.

Thus far, there has only been one econometric study of the effects of the trilemma on Malaysia's monetary policy in this period. Lim and Goh [3] tested for monetary independence but not interest rate independence by estimating capital account offset and sterilization coefficients. Their results suggest that even though BNM had some monetary control in the short run, it, however, lost its long-run monetary control during the peg/open capital period, and only re-captured control when it switched to managed floating ${ }^{1}$. Our study will differ from [3] in that we will use interest rate interdependence as the indicator for monetary independence. It will be interesting to see if a different indicator would suggest the same conclusions as the 2011 study; and why, if it should not.

The remainder of the paper is as follows. Section 2 deals with the theoretical framework and empirical methodology used in this paper. Section 3 reports and discusses the test results. The main conclusions and policy implications can be found in the last section.

\section{The Model And the Methodology}

We illustrate the underlying monetary independence hypothesis using the uncovered interest parity condition (UIP). The UIP is expressed as:

$$
i_{t}-i_{t}^{*}=E\left(s_{t+1}-s_{t}\right)+\rho
$$

where $i$ is the nominal interest rate, $i^{*}$ is the base country interest rate $^{2}, s$ is the exchange rate, $E$ is the expectation

\footnotetext{
${ }^{1}$ For the period prior to the Asian Currency Crisis (managed floating), Takagawa[4] and Umezaki [5] also found that Malaysia enjoyed some degree of monetary independence.

${ }^{2}$ The base country is the economy in which a country is pegged.
} 
operator, $\rho$ is the risk premium and $t$ is the time operator.

Under a fixed exchange rate regime, $s_{t}$ is constant. In a fully credible peg, we would expect that $E\left(s_{t+1}\right)$ remain the same, hence, the third term can be dropped as zero. Similarly, in the absence of any risk premium, $\rho$ is expected to be zero.

Hence, for a credible peg under open capital account, the domestic interest rates are expected to move one-for-one with the base country interest rates, that is:

$$
\Delta i_{t}=\Delta i_{t}^{*}
$$

In other words, there is a loss of monetary autonomy under a fixed exchange rate and an open capital regime.

Under a floating exchange rate regime, the domestic and base country interest rates are independent and only the spot exchange rate $(e)$ adjusts to satisfy the UIP condition. The expected change in exchange rate is equal to interest rate differential and the risk premium, $\rho$.

$$
E\left(s_{t+1}-s_{t}\right)=i_{t}-i_{t}^{*}-\rho
$$

This suggests that economies having floating exchange rate regimes experience less correlations between domestic and base country interest rate changes, and hence, have more monetary autonomy than do economies with fixed exchange rate regimes. If domestic monetary policy is independent of monetary policy in the base country, we would expect no cointegrating relationship between the interest rates. If the domestic interest rate follows tightly the movements in the base country's interest rate, then the domestic monetary policy is likely to be dependent on the base country's monetary policy; and we would expect a strong cointegrating relationship between the two interest rates. Nevertheless, our cointegration test implicitly imposes a conditional relationship between the US and Malaysian interest rate, i.e. for a small country like Malaysia, the interest rate does not Granger-cause the US interest rate. In other words, we are establishing cointegration with weak exogeneity of the Malaysian interest rate.

Prior to the cointegration test, we would conduct unit root tests to determine whether the variables are non-stationary (i.e. have unit roots). If all the variables studied are $I$ (1) non-stationary, we would proceed to the Johansen maximum likelihood method [6]-[8] to test whether these variables are cointegrated. The Johansen approach allows the testing of the long-run relationship between the variables in a multivariate framework, and requires that all the variables be of equal degree of integration to yield estimators which are super-consistent.

\section{DATA DESCRIPTION AND EMPIRICAL RESULTS}

We used the Malaysian interbank overnight and US Federal Fund rates as an indication of policy rate to examine whether interest rates in Malaysia are forced to follow a relationship with US interest rates, or whether some deviation is possible.

The US interest rate data were extracted from the Board of Governors of the Federal Reserve System, Economic Research and data website while the Malaysian interbank rates were extracted from Bank Negara Malaysia, Monthly Statistics Bulletin.

Unit root testing using the Augmented Dickey-Fuller (ADF) test, Phillips-Perron (PP) test and Augmented Dickey-Fuller Generalised Least Square (ADF-GLS) were carried out and are reported in Table I. All of these unit root tests were used to test whether the data contains unit root (non-stationary) or is a stationary process. All the tests cannot reject the null hypothesis of a unit root in levels, but are stationary after first differencing, implying that the variables under investigation are non-stationary at all levels.

\begin{tabular}{|c|c|c|}
\hline \multicolumn{3}{|c|}{$\begin{array}{l}\text { Panel 1: } \\
\text { Augmented Dickey Fuller (ADF) and Phillips Perron Test(PP) }\end{array}$} \\
\hline & \multicolumn{2}{|c|}{$2001: 1-2005: 6$} \\
\hline & $M I$ & USI \\
\hline & \multicolumn{2}{|c|}{$\mathrm{ADF}$} \\
\hline Level & $-2.23(3)$ & \\
\hline $1^{\text {st }}$ Difference & \multicolumn{2}{|r|}{$-2.90 *(4)$} \\
\hline & \multicolumn{2}{|c|}{$\mathrm{PP}$} \\
\hline Level & $-2.12(3)$ & $-2.06(0)$ \\
\hline $1^{\text {st }}$ Difference & $-14.17 *(2)$ & $-3.05 *(7)$ \\
\hline \multicolumn{3}{|l|}{ Panel 2: } \\
\hline \multicolumn{3}{|c|}{ Augmented Dickey Fuller - Generalized Least Square (ADF-GLS) } \\
\hline & \multicolumn{2}{|c|}{$2001: 1-2005: 6$} \\
\hline & $M I$ & USI \\
\hline & \multicolumn{2}{|c|}{ Test-stat } \\
\hline & $-2.23(3)$ & $-0.57(1)$ \\
\hline \multirow[t]{2}{*}{$1^{\text {st }}$ Difference } & $-4.15^{*}(3)$ & $-2.78 *(2)$ \\
\hline & \multicolumn{2}{|c|}{$95 \% \mathrm{BCV}$} \\
\hline Level & -2.36 & -2.25 \\
\hline $1^{\text {st }}$ Difference & -2.19 & -2.24 \\
\hline
\end{tabular}

TABLE I: UNIT ROOT TESTS

Note: $*$ denotes the significant rejection of unit root. Sub-sample consists of 92, 55 and 89 observations respectively. The ADF and the ADF_GLS include an intercept but not a trend. The $95 \%$ BCV are bootstrapped critical values by stochastic simulations using 1000 replications. The parenthesis in both tests refers to the optimal lags which were determined using Schwarz Bayesian Criterion. For fixing the truncated lag in PP test, the spectral estimation method selected is Bartlett kernel and for Bandwidth the Newey-West method. The optimal lag for ADF and ADF-GLS tests is selected based on the SIC criteria. The lag parameter was chosen to eliminate serial correlation in the estimated residuals.

However, the unit root test is notorious for its inability to reject the null hypothesis of unit root when there is a structural break in the variable [9]. In other words, for the series that are found to be nonstationary, there may be a possibility that they are in fact stationary around the structural break(s). Though our data span is not long, we cannot rule out the fact that there is some economic shock which causes a structural break in the interest rate data. If it is certain that the underlying series are all $I(1)$, the conventional Johansen cointegration techniques can be safely used. Thus, we opted to examine the unit root test which takes into account the endogenous structural breaks such as the Zivot-Andrew test.

We proceeded with three models to test for a unit root: (1) model A, which permits a one-time change in the level of the series; (2) model B, which allows for a one-time change in the slope of the trend function, and (3) model C, which combines one-time changes in the level and the slope of the trend function of the series. Hence, to test for a unit root against the alternative of a one-time structural break, Zivot and Andrews use the following regression equations corresponding to the above three models. 


$$
\begin{gathered}
\Delta Y_{t}=\mu+\alpha Y_{t-1}+\theta_{1} D U(\lambda)+\delta t+e_{1 t} \quad(\text { Model A) } \\
\Delta Y_{t}=\mu+\alpha Y_{t-1}+\theta_{1} D T(\lambda)+\delta t+e_{2 t} \quad \text { (Model B) } \\
\Delta Y_{t}=\mu+\alpha Y_{t-1}+\theta_{1} D U(\lambda)+\theta_{2} D T(\lambda)+\delta t+e_{3 t} \text { (ModelC) }
\end{gathered}
$$

where $D U$ is an indicator dummy variable for a mean shift occurring at each possible break-date (TB) while DT is the corresponding trend shift variable. The null hypothesis in all the three models is $\alpha=0$, which implies that the series $\left\{Y_{t}\right\}$ contains a unit root with a drift that excludes any structural break, while the alternative hypothesis $\alpha<0$ implies that the series is a trend-stationary process with a one-time break occurring at an unknown point in time. The Zivot and Andrews method regards every point as a potential break-date (TB) and runs a regression for every possible break-date sequentially. From amongst all possible break-points (TB), the procedure selects as its choice of break-date (TB) the date which minimizes the t-statistic.

Table II shows the Zivot-Andrew unit root test which allows for a single break in the intercept, the trend and both. Table II shows that using models A, B and C, we do not reject the null of unit root for MI and USI during this period, suggesting that both series are non -stationary even after taking account of the structural break. Since we are certain that the underlying series are all I (1), the conventional

\begin{tabular}{|c|c|c|}
\hline & \multicolumn{2}{|c|}{ 2001m5: $2005 \mathrm{~m} 6$} \\
\hline & Variable: Mi & Variable: USI \\
\hline \multicolumn{3}{|c|}{ Model A (intercept) } \\
\hline$K$ & 3 & 1 \\
\hline $\min t$ & -4.52 & -3.37 \\
\hline TB & 2002M06 & $2004 \mathrm{~m} 07$ \\
\hline \multicolumn{3}{|c|}{ Model B (Trend) } \\
\hline$K$ & 3 & 1 \\
\hline $\min t$ & -3.16 & $2002 \mathrm{~m} 07$ \\
\hline $\mathrm{TB}$ & -3.71 & $2004 \mathrm{~m} 02$ \\
\hline \multicolumn{3}{|c|}{ Model C (intercept and trend) } \\
\hline$K$ & 3 & 1 \\
\hline $\min t$ & -4.44 & $2002 \mathrm{~m} 06$ \\
\hline TB & -3.67 & $2004 \mathrm{~m} 02$ \\
\hline
\end{tabular}
Johansen cointegration techniques can be safely used.

TABLE II: ZIVOT-ANDREW TEST

Note: Model A which permits a structural break takes the form of a shift in the mean, Model B is where the structural break takes the form of a shift in the trend, and Model $\mathrm{C}$ allows the structural break to take the form of a shift in the mean and the trend. $K$ is the optimal lag length min $t$ is the Zivot-Andrew test statistics which is defined as the minimum t-statistics of all the sequential $t$-tests. TB is the break date that corresponds to the minimum $t$ statistics. Symbols *, **, *** denote significance at $10 \%, 5 \%$ and $1 \%$ levels respectively, using the critical values from Table II- Table IV from [10].

To implement the Johansen's cointegration test, the following VECM is estimated.

$$
\Delta X_{t}=\Phi D_{t}+\sum_{i=1}^{k-1} \Gamma_{i} \Delta X_{t-i}+\Pi X_{t-1}+\varepsilon_{t}
$$

where $\Delta$ is the first difference operator, $X_{t}$ is a vector of endogenous variables, and, $D_{t}$ is the deterministic vector. The matrix $\pi$ contains information about the long run relationship between $X_{t}$ variables in the vector.

The specification of a VECM requires the selection of a lag length for the VAR, followed by the selection of the number of cointegrating vectors and the appropriate deterministic specification. The selection of the lag length for the VAR can validly be done by estimating a VAR in the levels of the time series and using the usual information criteria and residual correlograms. Given a limited sample size and following the general rule of thumb for monthly data, a maximum lag length of six is sufficient to be imposed on the VAR model. The Akaike Information Criterion (AIC) suggests four-lags or VAR (4) model. According to the AIC criterion, two lags are included in the cointegration test.

We will consider including constant terms and linear time trends in a VECM. There are two places in the VECM where deterministics can be included: in the cointegration equations or in the error correction equations. We include a dummy variable in the cointegration estimations to be consistent with the structural break - unit root test. There are two hypothesis tests used for cointegration testing, called the Trace and Maximum Eigenvalue tests. Table III reports the estimated trace test statistics without and with break dates, respectively. Overall, the cointegrating rank is found to be 1 .

TABLE III: RESULTS OF JOHANSEN TRACE TEST WITH AND WITHOUT BREAK DATE ( $P$-VALUE)

\begin{tabular}{lll}
\hline$M I, U S I$ & $r=0$ & $r=1$ \\
\hline $\begin{array}{l}\text { Intercept and no trend, without break } \\
\text { dates }\end{array}$ & 0.0120 & 0.248 \\
$\begin{array}{l}\text { Intercept and no trend, with break } \\
\text { dates }\end{array}$ & 0.0131 & 0.330 \\
\hline
\end{tabular}

Note: The break dates are based on the dates suggested in the unit root tests. The $p$-values are based on [11] critical values taking into account the break date(s).

The trace statistics reveal that there is at least one linear combination in the long run, and hence, there is a long run equilibrium relationship between the Malaysian interest rate and US interest rate. The evidence of cointegration between the Malaysian interest rate and US interest rate during the period of fixed exchange rate regime and open capital account suggest that Malaysia did not possess monetary autonomy during this period, thus, implying that Malaysia is not exempted from the impossible trinity.

Nevertheless we need to estimate the short-and long-run parameters to make further inferences. In this study, we employ three different cointegrating estimators to estimate the long-run coefficients as shown in Table IV. Among them are the Maximum Likelihood Estimator (MLE) as proposed by [8], the Dynamic OLS (DOLS) approach as suggested by [12], and the Fully-Modified OLS (FMOLS) approach as suggested by [13]. This is to check for the robustness of the estimation results and also to provide more efficient estimates in our relatively small sample study. Moreover, the results in Table IV show that the US interest rate is 
statistically significant across the different cointegrating equation estimators.

TABLE IV: THE LONG-RUN ESTIMATES

\begin{tabular}{llcc}
\hline & MLE & FMOLS & DOLS \\
\hline Intercept & $1.56^{* * *}$ & $3.74^{* *}$ & $2.00^{* * *}$ \\
& $(0.12)$ & $(0.26)$ & $(0.34)$ \\
USI & $0.31^{* * *}$ & $0.44^{* * *}$ & $0.20^{* *}$ \\
& $(0.10)$ & $(0.09)$ & $(0.09)$ \\
Dummy & $1.13^{* * * *}$ & $3.74^{* * *}$ & $0.70^{* * *}$ \\
& $(0.20)$ & $(0.26)$ & $(0.23)$ \\
\hline
\end{tabular}

Note: We estimate $r$ on $r^{*}$ where $\mathrm{r}$ is the interest rate in Malaysia and $r^{*}$ is the interest rate in US. Our model includes an intercept and the dummies for period 2002:6 onwards. For DOLS, the lags and leads are each set to 1 and 1 . For FMOLS, the optimal lags were set using the AIC criteria. Parentheses indicate standard error. $* * *$ and $* * *$ denote significant levels at $10 \%, 5 \%$ and $1 \%$ respectively.

The Error-Correction Model (ECM) is estimated to derive the short-run parameters as shown below:

$$
\begin{array}{rr}
\Delta m i_{t}=0.015-0.41 E C T_{t-1}-0.71 \Delta m i_{t-1} \\
(0.02) \quad(0.09) & (0.31) \\
-0.97 \Delta m i_{t-2}-0.21 \Delta m i_{t-3}-0.24 \Delta m i_{t-4} \\
(0.26)
\end{array}
$$

$+0.44 \Delta u s i_{t-1}+0.22 \Delta u s i_{t-2}+0.20 \Delta u s i_{t-3}$

$+0.42 \Delta u s i_{t-4}+0.60 \Delta d u m_{t-1}-0.33 \Delta d u m_{t-2}$

$$
(0.22) \quad(0.31)
$$

$$
-0.47 \Delta d u m_{t-3}-0.40 \Delta d u m_{t-4}
$$

$R^{2}=0.72, F$-stat=6.28, Log-likelihood=31.71, where the parentheses contain the standard errors.

The ECM shows that the Error Correction Term (ECT) is highly significant and negative suggesting that 41 percent of the disequilibrium is eliminated within one period (i.e. one month in this study). There is no $100 \%$ adjustment to eliminate the disequilibrium in a single month; we interpret that BNM does retain some short run monetary autonomy during the period concerned. We attribute this short term monetary autonomy to sterilization activities conducted by BNM [3]. BNM undertook active sterilization operations to absorb the capital inflows to avoid excessive liquidity in the domestic financial market since the installation of the fixed exchange rate regime.

\section{CONCLUDING REMARKS}

We used a cointegration framework to examine whether Malaysian interest rates are driven by the US's interest rates during the fixed exchange and open capital account regime. We were careful in determining the order of integration of the underlying variables in the model prior to the cointegration test. This is important to ensure that Johansen cointegration test is an appropriate test in this study.
Upon very careful inspection of the Johansen tests, we found evidence that Malaysia's interest rate cointegrated with the interest rate in the US during the period of fixed exchange rate and open capital account regimes, suggesting that Malaysia is not exempted from the impossible trinity.

Our empirical results suggest that the trinity was at work for Malaysia during the periods of this investigation. It is not possible to have a fixed exchange rate, monetary policy autonomy, and open capital markets at the same time. Our study demonstrates that fixed exchange rates involve a loss of monetary policy autonomy. If a country wants to have its own monetary policy, then, it has to let the exchange rate float freely in an open capital account regime. In other words, a combination of an open capital account, a fixed exchange rate and an independent monetary policy is not possible. That explains why Malaysia moved away from a fixed exchange rate to a managed float on 21 July, 2005.

\section{REFERENCES}

[1] L. E. Ohanian and A. C. Stockman, "Short-run independence of monetary policy under pegged exchange rates and effects of money on exchange rates and interest rates," Journal of Money, Credit and Banking, vol. 29, no. 4, pp. 783-806, 1998.

[2] L. Svensson, "Why exchange rate bands? Monetary independence in spite of fixed exchange rates," Journal of Monetary Economics, vol. 33, pp. 157-199, 1994.

[3] E. G. Lim, and S. K. Goh, "Is Malaysia exempted from impossible trinity: Evidence from 1991 to 2009," CenPRIS Working Paper, 139/11, 2011.

[4] I. Takagawa, "An empirical analysis of the impossible trinity," in Exchange Rates, Capital Flows and Policy, ed, R. Driver, Sinclair, and C. Thoenissen, UK: Routledge, 2005, pp. 15-30.

[5] S. Umezaki, "Monetary policy in a small open economy: The case of Malaysia," The Developing Economies, vol. XLV-4, pp. 437-464, 2007.

[6] S. Johansen, "Statisical analysis of cointegrating vector," Journal of Economic Dynamics and Control, vol. 12, pp. 231-254, 1988.

[7] S. Johansen, "Estimation and hypothesis testing of cointegration vectors in Gaussian vector autoregressive models," Econometrica, vol. 59, pp. 1551-1580, 1991.

[8] S. Johansen and K. Juselius, "Maximum likelihood estimation and inference on cointegration with applications to the demand for money," Oxford Bulletin of Economics and Statistics, vol. 52, pp. 169-210, 1990.

[9] P. Perron, "The great crash, the oil price shock and the unit root hypothesis," Econometrica, vol. 57, pp. 1361-1401, 1989.

[10] E. Zivot and D. Andrews, "Further evidence of the great crash, the oil-price shock and the unit-root hypothesis," Journal of Business and Economic Statistics, vol. 10, pp. 251-270, 1992.

[11] S. Johansen, R. Mosconi, and B. Nielsen, "Cointegration analysis in the presence of structural breaks in the deterministic trend," Econometrics Journal, vol. 3, pp. 216-49, 2000.

[12] J. H. Stock and M. W. Watson, "A simple estimator of cointegrating vectors in higher order integrated systems," Econometrica, vol. 61, no. 4, pp. 783-820, 1993.

[13] P. C. B. Phillips and B. E. Hansen, "Statistical inference in instrumental variable regression with I(1) processes," Review of Economic Studies, vol. 57, no. 1, pp. 99-125, 1990.

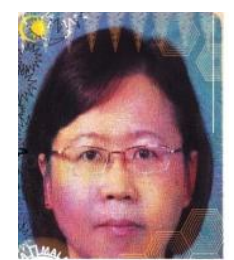

Soo Khoon Goh is a senior lecturer at the Centre for Policy Research and International Studies in Universiti Sains Malaysia. Science University of Malaysia, Penang, Malaysia. She has a B. Economics from University Malaya, Malaysia, M.Sc. in Economics from University of Colorado Boulder, USA, and a Ph.D. in Economics from University of Melbourne, Australia. Her main research interests lie in macroeconomics and international economics. She has published in reputable international journals such as Applied Economics, Asian Economic Journal, Journal of Asian Economics, Applied Economics Letters, Journal of Business Economics and Management, Economic Modeling. She is also a Fulbright Scholar, 2012-2013. 